\title{
Antibiotic resistance and NG-MAST sequence types of Neisseria gonorrhoeae isolates in Poland compared to the world
}

\author{
Beata Mlynarczyk-Bonikowska' ${ }^{1}$ Magdalena Malejczyk ${ }^{1}$, Sławomir Majewski², Magnus Unemo \\ ${ }^{1}$ Department of Diagnostics of Sexually Transmitted Diseases, Medical University of Warsaw, Warsaw, Poland \\ 2Department of Dermatology and Venereology, Medical University of Warsaw, Warsaw, Poland \\ ${ }^{3}$ World Health Organization (WHO) Collaborating Centre for Gonorrhoea and other STIs, Faculty of Medicine and Health, \\ Örebro University, Örebro, Sweden
}

Adv Dermatol Allergol 2018; XXXV (6): 546-551

DOI: https://doi.org/10.5114/ada.2018.79780

\begin{abstract}
Gonorrhoea is one of the most common sexually transmitted infections and in 2012, the World Health Organization estimated about 78 million of new global urogenital cases among adults per year. The main concern during the latest decade has been the emergence and spread of multidrug-resistant strains of Neisseria gonorrhoeae. Resistance has emerged internationally to the extended-spectrum cephalosporins, ceftriaxone and cefixime, which are the last remaining options for empiric first-line monotherapy of gonorrhoea. In Poland, the levels of resistance to ciprofloxacin, benzylpenicillin and tetracycline are high, and the prevalence of azithromycin resistance has increased. However, no resistance to ceftriaxone has been identified. The currently spread multidrug-resistant strains frequently represent epidemic clones. The present paper reviews and describes the antimicrobial resistance and N. gonorrhoeae multiantigen sequence typing (NG-MAST) sequence types of $\mathrm{N}$. gonorrhoeae strains spreading in Poland compared to the world.
\end{abstract}

Key words: Neisseria gonorrhoeae, gonorrhoea, antimicrobial resistance, ceftriaxone, azithromycin, NG-MAST, sequence type, genogroup.

\section{Introduction}

Neisseria gonorrhoeae is the etiological agent of gonorrhoea, one of the most common bacterial sexually transmitted infections. In 2012, the World Health Organization (WHO) estimated about 78 million of new global urogenital cases among adults per year [1]. Laboratory diagnostics of gonorrhoea includes microscopy, nucleic acid amplification tests (NAATs), and in vitro culture. Culture is the only method that allows for antimicrobial susceptibility testing and accordingly the culture remains essential [2]. Initially, N. gonorrhoeae showed a high susceptibility to many classes of antimicrobials and the treatment of gonorrhoea did not pose any major problems. However, since the first antimicrobials (sulfonamides) were introduced for treatment of gonorrhoea in the mid-1930s, N. gonorrhoeae has shown an extraordinary capacity to develop or acquire resistance to all therapeutic antimicrobials recommended. At present, internationally there is a high prevalence of $N$. gonorrhoeae strains with resistance to majority of antimicrobials earlier and currently widely used for treatment (e.g., sulfonamides, penicillins, earlier generation cephalosporins, tetracyclines, earlier generation macrolides and fluoroquinolones) [3]. In the mid-1990s, the first strains resistant to ceftriaxone and cefixime, the last remaining options for empiric first-line monotherapy of gonorrhoea, emerged in Japan [4], and subsequently started to spread internationally. In the recent decade, decreased susceptibility or resistance to ceftriaxone and cefixime has been reported in most countries worldwide [5]. This development is a major public health concern and in 2017, N. gonorrhoeae was included on the WHO list of 12 antibiotic-resistant pathogens that pose a global threat to human health and require priority efforts towards developing new antibiotics [6].

\section{Antimicrobial resistance of $N$. gonorrhoeae isolates in Poland}

In Poland, no gonococcal isolates with resistance to ceftriaxone have been identified [7-10]. However, the

Address for correspondence: Prof. Slawomir Majewski MD, PhD, Department of Dermatology and Venereology, Medical University of Warsaw, 82 A Koszykowa St, 02-008 Warsaw, Poland, phone: +48 22502 13 13, fax: +48 22502 13 13, e-mail: slawomir.majewski@wum.edu.pl Received: 15.05.2018, accepted: 12.06 .2018$. 
proportion of isolates with decreased susceptibility to these antibiotic has increased, including the rate of isolates with a ceftriaxone minimum inhibitory concentration (MIC) of $0.125 \mathrm{mg} / \mathrm{l}$ (exactly at the resistance breakpoint) $[8,9]$. In 2016 resistance to cefixime was detected first time (5.3\% of isolates from Poland in Euro-GASP). The prevalence of azithromycin-resistant isolates in 2010-2015 ranged from $5.4 \%$ to $19.0 \%$ [7, 8, 10, 11]. Some azithromycin-resistant strains belonging to the Neisseria gonorrhoeae multiantigen sequence typing (NG-MAST) genogroups G1407, G1478, and G21 exhibited a C2611T mutation in all the four $23 \mathrm{~S}$ rRNA alleles, which result in an azithromycin MIC of 4-32 mg/l [12]. The prevalence of ciprofloxacin-resistant isolates in 2010-2015 varied from $50.0 \%$ to $71.7 \%[7,8,10,13]$. Most isolates were resistant or intermediately resistant, with only $2.8 \%$ and $1.7 \%$ of strains susceptible, to benzyl penicillin, in 2012 and 2013, respectively $[8,9]$. The prevalence of penicillinase-producing $N$. gonorrhoeae (PPNG) strains has been mainly low $[8,9,14]$ illustrating that most of the resistance to benzyl penicillin is chromosomally-mediated. The prevalence of tetracycline-resistant isolates in 2010-2013 ranged from $38.0 \%$ to $50.8 \%[8,15]$.

\section{Antimicrobial resistance of $N$. gonorrhoeae isolates all over the world}

In the recent decade, $N$. gonorrhoeae isolates with decreased susceptibility or resistance to ceftriaxone and cefixime have been identified in most countries globally [5]. The first gonococcal strain with high-level resistance to ceftriaxone $(\mathrm{MIC}=2 \mathrm{mg} / \mathrm{l})$ and cefixime $(\mathrm{MIC}=4 \mathrm{mg} / \mathrm{l})$ was isolated in Kyoto, Japan, in 2009 [16, 17]. Another strain with high-level resistance to ceftriaxone and cefixime (MICs of $1 \mathrm{mg} / \mathrm{l}$ and $2 \mathrm{mg} / \mathrm{l}$, respectively) was isolated in France in 2010 [18], and two isolates similar to the French strain were later identified in Spain in 2012 [19]. None of these strains appear to have spread further $[5,10,20-26]$, which is likely due to a suboptimal biological fitness of these strains [27]. Subsequently, additional sporadic ceftriaxone-resistant isolates with a ceftriaxone MIC of $\geq 0.5 \mathrm{mg} / \mathrm{l}$ have also been characterized in more detail during the latest years, for example, isolates from Australia in 2013 and 2017 [28, 29], Argentina in 2014 [30], Japan in 2014 and 2015 [31, 32], Denmark in 2017 [33], and Canada in 2017 [34]. Retrospective studies in China [35-37] and Japan [38] have also identified relatively high proportions of ceftriaxone-resistant isolates. It is a grave public health concern that the first three N. gonorrhoeae isolates globally with resistance to ceftriaxone combined with high-level resistance to azithromycin (MIC $\geq 256 \mathrm{mg} / \mathrm{l}$ ) were identified at the beginning of 2018 in the United Kingdom (1 case) [39] and a few months later in Australia (2 cases) [40]. These gonococcal strains pose a main threat to the first-line dual antimicrobial therapy (ceftriaxone of 250-500 mg administered intramuscu- larly plus azithromycin of 1-2 g administered orally) recommended in Europe [41] and other settings worldwide.

In the European Gonococcal Antimicrobial Surveillance Programme (Euro-GASP), 26 (0.26\% of 9910 isolates) ceftriaxone-resistant isolates were reported from 2011 to 2015 (10 in 2011), 3 in 2012, 7 in 2013, 5 in 2014 and 1 isolate in 2015). These ceftriaxone-resistant isolates were cultured in Greece $(n=4)$, Spain $(n=6)$, Germany $(n=10)$ and Austria $(n=3)$, and one isolate each in Norway, Ireland, and Slovenia [10, 21-25]. Resistance rates to cefixime have been substantially higher and, in 20122014, cefixime-resistant isolates were found in most European countries; in 2013, their prevalence was highest in Spain (15.1\%) and Greece (14.5\%), and in 2014, in Belgium (12.1\%). Resistance to azithromycin has also been found in nearly all European countries (except for Estonia and Iceland), with the highest prevalence in Greece (39.6\%) and Ireland (37.6\%) in 2014, and in Greece (22.7\%) in 2013. Resistance to ciprofloxacin was found in all European countries, with the highest rates (more than 70\%) in Austria, Greece, and Germany, and the lowest in Estonia (2.0\%); PPNG strains were most common in Austria, Sweden, and Norway [10, 21-24].

The prevalence of resistance to cefixime, azithromycin, ciprofloxacin in various countries stratified by years is presented in Table 1. For countries continuously participating in Euro-GASP, the presented resistance data span 2012-2015 [10, 21-25]. Moreover, resistance data from some non-EU/EEA WHO European region countries (Belarus and Russia) have been included [42-45].

\section{Molecular epidemiological typing of $N$. gonorrhoeae}

Molecular epidemiological typing, particularly linked to antimicrobial resistance and epidemiological data of patients, can be exceedingly valuable. The typing can identify the spread of antimicrobial resistant strains, potentially more virulent strains, and describe changing strain distributions overall and among risk groups $[46,47]$.

For N. gonorrhoeae, NG-MAST has been the most frequently used molecular typing method [8, 12, 46-48]. NG-MAST includes sequencing of parts of two more variable genes: por $B$ (encoding the transmembrane channel proteinporin $B($ Por $B)$ ) and $t b p B$ (encoding the transferrin-binding protein $B(T b p B)$ ). The sequences are subsequently assigned allele numbers and, at present, more than 9800 porB alleles and 2,700 tbpB alleles have been described. The combination of the por $B$ and $t b p B$ allele number is assigned an NG-MAST sequence type (ST). At present, approximately 16,800 NG-MAST STs have been described (www.ng-mast.net).

The proportions of different NG-MAST STs in different countries have been summarized in Table 2 [8, 35, 36, 42-44, 49-57]. Briefly, in 2009-2010, the most common STs in Europe were as follows: ST1407 (15.6\%) of genogroup G1407; 
Table 1. Antimicrobial resistance of Neisseria gonorrhoeae in the European Union (EU)/European Economic Area (EEA) and some non-EU/EEA WHO European region countries (Belarus and Russia)

\begin{tabular}{|c|c|c|c|c|c|}
\hline \multirow[t]{2}{*}{ Country } & \multirow[t]{2}{*}{ Year } & \multicolumn{3}{|c|}{$\%$ of resistance } & \multirow[t]{2}{*}{ PPNG (\%) } \\
\hline & & CFX & $A Z T$ & CIP & \\
\hline Austria* & $2012 / 13 / 14 / 15$ & $5 / 6 / 0 / 0$ & $3 / 6 / 2 / 3$ & $74 / 72 / 53 / 66$ & $32 / 26 / 24 / 32$ \\
\hline Belarus & $2012 / 13$ & $0 / 3$ & $1 / 0$ & $21 / 28$ & $0 / 0$ \\
\hline Belgium* & 2012/13/14/15 & $1 / 6 / 12 / 11$ & $2 / 2 / 4 / 3$ & $56 / 56 / 58 / 50$ & $10 / 16 / 19 / 14$ \\
\hline Croatia* & 2015 & 0 & 0 & 38 & 13 \\
\hline Cyprus* & 2015 & 0 & 0 & 67 & 0 \\
\hline Denmark* & 2012/13/14/15 & $12 / 12 / 6 / 0$ & $14 / 9 / 4 / 3$ & $59 / 58 / 33 / 31$ & $18 / 8 / 9 / 9$ \\
\hline Estonia* & $2014 / 15$ & $0 / 0$ & $0 / 0$ & $2 / 28$ & $0 / 0$ \\
\hline France $^{*}$ & 2012/13/14/15 & $2 / 4 / 1 / 0$ & $0 / 0 / 11 / 6$ & $39 / 45 / 51 / 42$ & 7/33/ND/ND \\
\hline Germany* & 2012/13/14/15 & $6 / 13 / 0 / 2$ & $2 / 4 / 3 / 2$ & $74 / 63 / 63 / 62$ & 19/17/13/16 \\
\hline Greece $^{*}$ & 2012/13/14/15 & $6 / 15 / 5 / 11$ & $6 / 23 / 40 / 22$ & 69/72/70/77 & $12 / 3 / 6 / 11$ \\
\hline Hungary* & $2012 / 13 / 14 / 15$ & $6 / 7 / 1 / 2$ & $0 / 2 / 1 / 5$ & $66 / 68 / 55 / 53$ & $1 / 7 / 14 / 14$ \\
\hline Iceland* & $2013 / 14 / 15$ & $0 / 0 / 0$ & $0 / 0 / 0$ & $40 / 58 / 29$ & $\mathrm{ND} / 22 / 0$ \\
\hline Ireland* & 2012/13/14/15 & $4 / 0 / 0 / 1$ & $9 / 3 / 38 / 18$ & $23 / 26 / 35 / 46$ & $3 / 5 / 2 / 11$ \\
\hline Italy* & 2012/13/14/15 & $6 / 0 / 2 / 0$ & $2 / 1 / 6 / 2$ & $65 / 63 / 78 / 71$ & $9 / 9 / 8 / 7$ \\
\hline Latvia* & 2012/13/14/15 & $3 / 3 / 0 / 0$ & $5 / 16 / 14 / 0$ & $39 / 26 / 19 / 11$ & 0/13/0/0 \\
\hline Malta* & 2012/13/14/15 & 0/0/0/0 & $0 / 0 / 5 / 14$ & $56 / 36 / 57 / 66$ & $19 / 6 / 10 / 24$ \\
\hline Netherlands* & $2012 / 13 / 14 / 15$ & $0 / 0 / 2 / 1$ & $1 / 1 / 2 / 4$ & $34 / 35 / 32 / 37$ & ND/ND/ND/ND \\
\hline Norway* & 2012/13/14/15 & $6 / 5 / 6 / 1$ & $13 / 11 / 5 / 4$ & $56 / 80 / 74 / 59$ & $27 / 29 / 29 / 25$ \\
\hline Poland* & $2012 / 13 / 14 / 15$ & O/ND/0/0 & $10 / 19 / 9 / 5$ & $69 / 62 / 65 / 57$ & $4 / 9 / 0 / 5$ \\
\hline Portugal* & 2012/13/14/15 & 0/0/0/0 & 2/18/17/17 & $41 / 47 / 36 / 37$ & $8 / 6 / 7 / 8$ \\
\hline Russia & $2012 / 2015$ & $\mathrm{ND} / \mathrm{ND}$ & $17 / 2$ & $26 / 40$ & $0 / 0$ \\
\hline Slovakia* & $2012 / 13 / 14 / 15$ & $4 / 5 / 1 / 4$ & $3 / 2 / 4 / 2$ & $54 / 47 / 68 / 54$ & $6 / 4 / 25 / 26$ \\
\hline Slovenia* & 2012/13/14/15 & $4 / 1 / 1 / 0$ & $15 / 0 / 2 / 0$ & $40 / 63 / 45 / 35$ & $9 / 14 / 22 / 5$ \\
\hline Spain* & $2012 / 13 / 14 / 15$ & $15 / 15 / 0 / 2$ & $10 / 8 / 7 / 3$ & $58 / 66 / 68 / 65$ & $15 / 13 / 19 / 20$ \\
\hline Sweden* & 2012/13/14/15 & 0/0/0/0 & $6 / 9 / 4 / 14$ & $57 / 60 / 57 / 45$ & $31 / 18 / 19 / 13$ \\
\hline$U^{*}$ & 2012/13/14/15 & $0 / 1 / 0 / 0$ & $2 / 0 / 1 / 13$ & $28 / 32 / 33 / 40$ & $5 / 10 / 9 / 19$ \\
\hline $\mathrm{EU} / \mathrm{EEA}^{* *}$ & 2012/13/14/15 & $4 / 5 / 2 / 2$ & $5 / 5 / 8 / 7$ & $50 / 53 / 51 / 49$ & $13 / 13 / 14 / 15$ \\
\hline
\end{tabular}

${ }^{*}$ Countries participating in Euro-GASP included in the EU/EEA average, CFX - cefixime (MIC >0.125 mg/l), AZT-azithromycin (MIC >0.5 mg/l), CIP - ciprofloxacin (2012: MIC >0.5 mg/l; 2013-2015: MIC >0.064 mg/l), PPNG - penicillinase-producing Neisseria gonorrhoeae, ND - not done.

ST2992 (7.1\%) of G2992; and ST225 (4.7\%) of G225. ST1407 predominated in the European countries - Austria, Belgium, Italy, the Netherlands, Portugal, Romania, Slovenia, Spain, Switzerland, the United Kingdom [58], but also in Canada $[50,51]$ and the USA $[56,59]$. ST2992 predominated in Ireland and Norway, while ST225 predominated in Denmark, Sweden, and on Malta [58]. In 2013, the most frequent STs in Europe remained ST1407 (7.6\%) and ST2992 (6.7\%), with an increase in the rates of ST2400 (3.9\%, genogroup G2400). ST1407 predominated in Belgium, Hungary, Norway, Portugal, Slovenia, Spain and Switzerland. ST2992 predominated in Ireland, Italy, on Malta, in the Netherlands, and the United
Kingdom. ST2400 was detected in eight countries but was not the predominant ST in any of them [55].

In recent years, whole genome sequencing (WGS) has been increasingly used for epidemiological typing of N. gonorrhoeae. Compared to NG-MAST, WGS has a substantially higher and more accurate resolution and can identify multidrug-resistant clades linked to risk groups and additionally predict antimicrobial resistance with a relatively high sensitivity and specificity $[12,52,59,60]$. The WGS will likely be the method of choice for molecular epidemiology and in antimicrobial resistance surveillance of N. gonorrhoeae soon. However, appropriate funding, 
Table 2. Prevalence of NG-MAST sequence types in Europe and selected non-European countries

\begin{tabular}{|c|c|c|c|}
\hline Country & Year & Sequence type (ST) & \% ST \\
\hline Australia & 2011-2013 & 758/9716/7126 & 22/13/11 \\
\hline \multirow[t]{2}{*}{ Austria } & 2010 & $1407 / 387 / 359 / 5600$ & $32 / 10 / 8 / 8$ \\
\hline & 2013 & 3785/11575/4995/387/225 & $17 / 11 / 7 / 7 / 7$ \\
\hline Belarus & 2010-2013 & $1993 / 807 / 285 / 9735$ & $28 / 7 / 4 / 4$ \\
\hline \multirow[t]{2}{*}{ Belgium } & 2010 & $1407 / 387 / 2992$ & $14 / 12 / 8$ \\
\hline & 2013 & $1407 / 387 / 2992$ & $16 / 15 / 15$ \\
\hline \multirow[t]{5}{*}{ Canada } & 2010 & $1407 / 3150 / 3158$ & $13 / 12 / 9$ \\
\hline & 2011 & $1407 / 3307 / 3550$ & $15 / 10 / 6$ \\
\hline & 2012 & $1407 / 2400 / 3150$ & $11 / 7 / 7$ \\
\hline & 2013 & 2400/9663/5985 & $12 / 7 / 6$ \\
\hline & 2014 & $2400 / 5985 / 10451$ & $14 / 14 / 10$ \\
\hline China & 2012-2013 & $2318 / 1866 / 4846$ & $3 / 2 / 1$ \\
\hline \multirow[t]{2}{*}{ Denmark } & 2010 & $225 / 3158 / 1407$ & $12 / 12 / 6$ \\
\hline & 2013 & $1993 / 1407 / 2400$ & $18 / 13 / 7$ \\
\hline \multirow[t]{3}{*}{ France } & 2010 & $2 / 2992 / 1407$ & $14 / 14 / 8$ \\
\hline & 2013 & $645 / 11352 / 225 / 2400 / 2992 /$ & $9 / 5 / 4 / 4 / 4 /$ \\
\hline & & $3149 / 4995 / 5624 / 11357$ & $4 / 4 / 4 / 4$ \\
\hline \multirow[t]{2}{*}{ Germany } & 2010 & $25 / 1407 / 5425$ & $32 / 28 / 6$ \\
\hline & 2013 & $4995 / 25 / 359 / 5441 / 9500$ & $8 / 6 / 6 / 6 / 6$ \\
\hline \multirow[t]{2}{*}{ Greece } & 2010 & $5405 / 5505 / 1407$ & 16/16/12 \\
\hline & 2013 & $3128 / 225 / 4730 / 11055$ & $19 / 10 / 10 / 10$ \\
\hline Greenland & 2012-2013 & $210 / 9816 / 2400$ & $50 / 26 / 10$ \\
\hline \multirow[t]{2}{*}{ Hungary } & 2010 & $5332 / 356 / 1407 / 5333$ & $29 / 12 / 12 / 12$ \\
\hline & 2013 & 1407/995/387/8115/11046 & $21 / 13 / 6 / 6 / 6$ \\
\hline \multirow[t]{3}{*}{ Ireland } & 2010 & $2992 / 384 / 1407$ & $32 / 12 / 6$ \\
\hline & 2013 & 2992/384/21/437/10843/649/ & 16/11/4/4/ \\
\hline & & $2400 / 4643 / 10846$ & $4 / 4 / 4 / 4 / 4$ \\
\hline \multirow[t]{2}{*}{ Italy } & 2010 & $1407 / 2992 / 995$ & $34 / 10 / 10$ \\
\hline & 2013 & 2992/6360/2400/1407 & $18 / 12 / 12 / 10$ \\
\hline
\end{tabular}

\begin{tabular}{|c|c|c|c|}
\hline Country & Year & Sequence type (ST) & $\%$ ST \\
\hline \multirow[t]{2}{*}{ Latvia } & 2009-2010 & $3227 / 5185 / 5340 / 225$ & $41 / 10 / 7 / 7$ \\
\hline & 2013 & $5 / 10828 / 21 / 4269$ & $37 / 13 / 8 / 8$ \\
\hline \multirow[t]{2}{*}{ Malta } & 2009-2010 & $225 / 5463 / 1407 / 4949$ & $46 / 12 / 6 / 6$ \\
\hline & 2013 & 2992/484/10788/ & $33 / 14 / 14$ \\
\hline \multirow{2}{*}{ Netherlands } & 2010 & $1407 / 2992 / 5402 / 2400$ & $16 / 7 / 7 / 6$ \\
\hline & 2013 & 2992/2400/8919 & $10 / 10 / 6$ \\
\hline \multirow[t]{2}{*}{ Norway } & 2009-2010 & 2992/1407/4347 & $23 / 14 / 10$ \\
\hline & 2013 & $1407 / 4275 / 2400$ & $9 / 7 / 6$ \\
\hline Pakistan & 2012-2014 & 338/3328/10876/10886 & $3 / 3 / 3 / 3$ \\
\hline \multirow[t]{3}{*}{ Poland } & 2010 & $1405 / 5421 / 225$ & $18 / 18 / 14$ \\
\hline & 2011 & $1407 / 2992 / 8379$ & $13 / 13 / 9$ \\
\hline & 2012 & 1407/8391/1861/2992 & $43 / 7 / 5 / 5$ \\
\hline \multirow[t]{2}{*}{ Portugal } & 2009-2010 & 1407/1034/2992 & $14 / 8 / 8$ \\
\hline & 2013 & $1407 / 7445 / 2$ & $16 / 11 / 5$ \\
\hline Romania & 2010 & $1407 / 4120 / 3952 / 5330$ & $22 / 22 / 11 / 11$ \\
\hline \multirow[t]{2}{*}{ Russia } & 2011-2012 & $807 / 5714 / 228$ & $8 / 6 / 3$ \\
\hline & 2015 & 9476/807/1544/5714/12531 & $11 / 8 / 5 / 5 / 5$ \\
\hline \multirow[t]{2}{*}{ Slovakia } & 2010 & $437 / 5595 / 5598$ & $26 / 20 / 10$ \\
\hline & 2013 & $1407 / 359 / 11042$ & $14 / 14 / 13$ \\
\hline \multirow[t]{2}{*}{ Slovenia } & 2009-2010 & $1407 / 225 / 5570$ & 28/16/10 \\
\hline & 2013 & 21/10801/10800/10798 & $13 / 13 / 9 / 9$ \\
\hline \multirow[t]{2}{*}{ Spain } & 2009-2010 & 1407/2992/292/3149/1861 & $28 / 9 / 4 / 4 / 4$ \\
\hline & 2013 & $1407 / 7232 / 2992 / 21$ & $11 / 8 / 7 / 7$ \\
\hline \multirow[t]{2}{*}{ Sweden } & 2010 & 225/2992/5175/5177/5188/5210 & $8 / 6 / 6 / 6 / 6 / 6$ \\
\hline & 2013 & $5445 / 7445 / 7164$ & $10 / 6 / 6$ \\
\hline \multirow[t]{2}{*}{ Switzerland } & 2009 & $1407 / 2058$ & $38 / 25$ \\
\hline & 2011 & $1407 / 2992$ & $22 / 22$ \\
\hline United & 2010 & $1407 / 2 / 51$ & $14 / 6 / 6$ \\
\hline Kingdom & 2013 & 2992/51/4995 & $10 / 10 / 9$ \\
\hline USA & 2011 & $1407 / 7268 / 5895$ & $4 / 2 / 1$ \\
\hline
\end{tabular}

NG-MAST - Neisseria gonorrhoeae multiantigen sequence typing.

capacity building and quality assurance remain essential for this transition.

\section{Molecular epidemiological typing of $N$. gonorrhoeae isolated in Poland}

In Poland, N. gonorrhoeae isolates cultured in 20102012 have been examined by NG-MAST [8]. The most common STs in 2010 were ST5421 (17.9\%; G1479), ST1405 (17.9\%; G1405), and ST225 (14.3\%; G225). In 2011, the most prevalent STs were the multidrug-resistant ST1407 (13.0\%; G1407), ST2992 (13.0\%; G2992), and ST8379 (8.7\%; G8379). In 2012, nearly half of the isolates were assigned as ST1407 (44.3\%; G1407), followed by ST8391 (6.5\%; G5043), ST2992 (4.6\%; G2992), ST1861 (4.6\%; G1861), ST21 (3.7\%; G21), and ST8392 (3.7\%; G8392) [8].

\section{Conclusions}

The extensive spread of the multidrug-resistant N. gonorrhoeae NG-MAST G1407 in Europe, including Poland, has been raising major concerns. However, fortunately the prevalence of G1407 significantly decreased from 2009/2010 to 2013 in Europe [60] and no isolates resistant to ceftriaxone have been detected in Poland so far. Nevertheless, isolates with ceftriaxone MIC exactly at the ceftriaxone resistance breakpoint $(\mathrm{MIC}=0.125 \mathrm{mg} / \mathrm{l})$ have been identified in Poland and ceftriaxone-resistant isolates have been cultured in neighboring countries. In 2016 the first cefixime-resistant isolates were observed in Poland. Furthermore, sporadic ceftriaxone-resistant isolates belonging to other NG-MAST genogroups and with a ceftriaxone MIC of $\geq 0.5 \mathrm{mg} / \mathrm{l}$ have also been identified and characterized in more detail during the latest years, e.g. isolates from Australia [28, 29], Argentina [30], Japan 
[31, 32], Denmark [33] and Canada [34]. Recently the first three $N$. gonorrhoeae isolates in the world with resistance to ceftriaxone combined with high-level resistance to azithromycin (MIC $\geq 256 \mathrm{mg} / \mathrm{l}$ ) have been identified. Consequently, it is a major concern that $N$. gonorrhoeae strains with resistance to ceftriaxone will be introduced and spreading in Poland in the near future. An enhanced, quality assured surveillance of antimicrobial resistance and antimicrobial resistance determinants in $\mathrm{N}$. gonorrhoeae is essential in Poland, as well as in most other countries.

\section{Conflict of interest}

The authors declare no conflict of interest.

\section{References}

1. Newman L, Rowley J, Vander Hoorn S, et al. Global estimates of the prevalence and incidence of four curable sexually transmitted infections in 2012 based on systematic review and global reporting. PLoSOne 2015; 10: e0143304.

2. Mlynarczyk-Bonikowska B, Skulska E, Malejczyk M, et al. Nucleic acid amplification methods in laboratory diagnostics of selected sexually transmitted diseases. Post Mikrobiol 2015; 54: 407-14.

3. Unemo M, Shafer WM. Antimicrobial resistance in Neisseria gonorrhoeae in the $21^{\text {st }}$ century: past, evolution, and future. Clin Microbiol Rev 2014; 27: 587-613.

4. Shimuta K, Watanabe Y, Nakayama S, et al. Emergence and evolution of internationally disseminated cephalosporinresistant Neisseria gonorrhoeae clones from 1995 to 2005 in Japan. BMC Infect Dis 2015; 15: 378.

5. Wi T, Lahra MM, Ndowa F, et al. Antimicrobial resistance in Neisseria gonorrhoeae: global surveillance and a call for international collaborative action. PLoS Med 2017; 14: e1002344.

6. World Health Organization. Global priority list of antibioticresistant bacteria to guide research, discovery, and development of new antibiotics, publications/global-priority-listantibiotic-resistant-bacteria/en/Geneva 2017; http://www. who.int/medicines/

7. Unemo M, Ringlander J, Wiggins C, et al. High in vitro susceptibility to the novel spiropyrimidinetrione AZD0914 among contemporary clinical Neisseria gonorrhoeae isolates in 21 European countries. Antimicrob Agents Chemother 2015; 59: 5220-5.

8. Mlynarczyk-Bonikowska B, Serwin AB, Golparian D, et al. Epidemiology, antimicrobial susceptibility/resistance and genetic characteristics of Neisseria gonorrhoeae isolates from Poland, 2010-2012. BMC Infect Dis 2014; 14: 65.

9. Mlynarczyk-Bonikowska B, Kujawa M, Mlynarczyk G, et al. Susceptibility to ceftriaxone and penicillinase plasmids of Neisseria gonorrhoeae strains isolated in Poland in 20122013. Folia Microbiol 2016; 61: 269-73.

10. European Centre for Disease Prevention and Control. Gonococcal antimicrobial susceptibility surveillance in Europe, 2014. Stockholm: ECDC. 2016.

11. Mlynarczyk-Bonikowska B, Kujawa M, Mlynarczyk G, et al. Resistance to azithromycin of Neisseria gonorrhoeae strains isolated in Poland in 2012-2013 years. Med Dośw Mikrobiol 2014; 66: 209-14.
12. Jacobsson S, Golparian D, Cole M, et al. Whole genome sequence analysis and molecular resistance mechanisms in azithromycin resistant Neisseria gonorrhoeae isolates in Europe from 2009 to 2014. J Antimicrob Chemother 2016; 71: 3109-16.

13. Mlynarczyk-Bonikowska B, Kujawa M, Mlynarczyk G, et al. Resistance to ciprofloxacin of Neisseria gonorrhoeae strains isolated in Poland in 2012-2013. Med Dośw Mikrobiol 2014; 66: 99-104.

14. Mlynarczyk-Bonikowska B, Przedpełska G, Malejczyk M, et al. Penicillinase production by Neisseria gonorrhoeae strains isolated from the patients of Dermatology and Wenerology Clinic, Warsaw Medical University in 2006-2009. Med Dośw Mikrobiol 2011; 63: 115-20.

15. Mlynarczyk-Bonikowska B, Kujawa M, Malejczyk M, et al. Plasmid-mediated resistance to tetracyclines among Neisseria gonorrhoeae strains isolated in Poland in the period 2012-2013. Post Dermatol Alergol 2016; 33: 475-9.

16. Ohnishi M, Golparian D, Shimuta K, et al. Is Neisseria gonorrhoeae initiating a future era of untreatable gonorrhea? Detailed characterization of the first strain with high-level resistance to ceftriaxone. Antimicrob Agents Chemother 2011; 55: 3538-45.

17. Ohnishi M, Saika T, Hoshina S, et al. Ceftriaxone-resistant Neisseria gonorrhoeae, Japan. Emerg Infect Dis 2011; 17: 148-9.

18. Unemo M, Golparian D, Nicholas R, et al. High-level cefixime- and ceftriaxone-resistant N. gonorrhoeae in France: novel penA mosaic allele in a successful international clone causes treatment failure. Antimicrob Agents Chemother 2012; 56: 1273-80.

19. Cámara J, Serra J, Ayats J, et al. Molecular characterization of two high-level ceftriaxone-resistant Neisseria gonorrhoeae isolates detected in Catalonia, Spain. J Antimicrob Chemother 2012; 67: 1858-60.

20. Shimuta K, Unemo M, Nakayama S, et al. Antimicrobial resistance and molecular typing of Neisseria gonorrhoeae isolates in Kyoto and Osaka, Japan, 2010 to 2012: intensified surveillance after identification of the first strain ( $\mathrm{H041}$ ) with high-level ceftriaxone resistance. Antimicrob Agents Chemother 2013; 57: 5225-32.

21. European Centre for Disease Prevention and Control. Gonococcal antimicrobial susceptibility surveillance in Europe, 2012. Stockholm: ECDC. 2014.

22. European Centre for Disease Prevention and Control. Gonococcal antimicrobial susceptibility surveillance in Europe, 2013. Stockholm: ECDC. 2015.

23. Cole MJ, Spiteri G, Jacobsson S, et al. Overall low extendedspectrum cephalosporin resistance but high azithromycin resistance in Neisseria gonorrhoeae in 24 european countries, 2015. BMC Infect Dis 2017; 17: 617.

24. Cole MJ, Spiteri G, Jacobsson S, et al. Is the tide turning again for cephalosporin resistance in Neisseria gonorrhoeae in Europe? Results from the 2013 European surveillance. BMC Infect Dis 2015; 15: 321.

25. Cole MJ, Spiteri G, Chisholm SA, et al. Emerging cephalosporin and multidrug-resistant gonorrhoea in Europe. Euro Surveill 2014; 19: 20955.

26. Cole MJ, Unemo M, Hoffmann S, et al. The European gonococcal antimicrobial surveillance programme, 2009. Euro Surveill 2011; 16: pii: 19995.

27. Vincent $L R$, Kerr SR, Tan Y, et al. In vivo-selected compensatory mutations restore the fitness cost of mosaic penA 
alleles that confer ceftriaxone resistance in Neisseria gonorrhoeae. MBio 2018; 9: pii: e01905-17.

28. Lahra MM, Ryder N, Whiley DM. A new multidrug-resistant strain of Neisseria gonorrhoeae in Australia. N Engl J Med 2014; 371: 1850-1.

29. Lahra MM, Martin I, Demczuk W, et al. Cooperative recognition of internationally disseminated ceftriaxone-resistant Neisseria gonorrhoeae strain. Emerg Infect Dis 2018; 24: 735-40.

30. Gianecini R, Oviedo C, Stafforini G, et al. Neisseria gonorrhoeae resistant to ceftriaxone and cefixime, Argentina. Emerg Infect Dis 2016; 22: 1139-41.

31. Deguchi T, Yasuda M, Hatazaki K, et al. New clinical strain of Neisseria gonorrhoeae with decreased susceptibility to ceftriaxone, Japan. Emerging Infect Dis 2016; 22: 142-4.

32. Nakayama SI, Shimuta K, Furubayashi KI, et al. New ceftriaxone- and multidrug-resistant Neisseria gonorrhoeae strain with a novel mosaic penA gene isolated in Japan. Antimicrob Agents Chemother 2016; 60: 4339-41.

33. Terkelsen D, Tolstrup J, Johnsen $\mathrm{CH}$, et al. Multidrug-resistant Neisseria gonorrhoeae infection with ceftriaxone resistance and intermediate resistance to azithromycin, Denmark, 2017. Euro Surveill 2017; 22. doi: 10.2807/1560-7917.

34. Lefebvre B, Martin I, Demczuk W, et al. Ceftriaxone-resistant Neisseria gonorrhoeae, Canada, 2017. Emerging Infect Dis 2018; 24: 381-3.

35. Chen SC, Yin YP, Dai XQ, et al. Antimicrobial resistance, genetic resistance determinants for ceftriaxone and molecular epidemiology of Neisseria gonorrhoeae isolates in Nanjing, China. J Antimicrob Chemother 2016; 69: 2959-65.

36. Chen SC, Yin YP, Dai XQ, et al. First nationwide study regarding ceftriaxone resistance and molecular epidemiology of Neisseria gonorrhoeae in China. J Antimicrob Chemother 2016; 71: 92-9.

37. Yin YP, Han Y, Dai XQ, et al. Susceptibility of Neisseria gonorrhoeae to azithromycin and ceftriaxone in China: a retrospective study of national surveillance data from 2013 to 2016. PLoS Med 2018; 15: e1002499.

38. Yasuda M, Hatazaki K, Ito S, et al. Antimicrobial susceptibility of Neisseria gonorrhoeae in Japan from 2000 to 2015. Sex Transm Dis 2017; 44: 149-53.

39. Public Health England. Update on investigation of UK case of Neisseria gonorrhoeae with high-level resistance to azithromycin and resistance to ceftriaxone acquired abroad. https://assets.publishing.service.gov.uk/government/ uploads/system/uploads/attachment_data/file/701185/ hpr1418 MDRGC.pdf

40. Australian Government. Department of Health. Multi-drug resistant gonorrhoea 2018. http://www.health.gov.au/internet/main/publishing.nsf/Content/mr-yr18-dept-dept004. htm.

41. Bignell C, Unemo M. European STI Guidelines Editorial Board. 2012 European guideline on the diagnosis and treatment of gonorrhoea in adults. Int J STD AIDS 2013; 24: 85-92.

42. Kubanov A, Vorobyev D, Chestkov A, et al. Molecular epidemiology of drug-resistant Neisseria gonorrhoeae in Russia (Current Status, 2015). BMC Infect Dis 2016; 16: 389.

43. Lebedzeu F, Golparian D, Titov L, et al. Antimicrobial susceptibility/resistance and NG-MAST characterization of Neisseria gonorrhoeae in Belarus, Eastern Europe, 2010-2013. BMC Infect Dis 2015; 15: 29.

44. Kubanova A, Kubanov A, Frigo N, et al. Russian gonococcal antimicrobial susceptibility programme (RU-GASP): resistance in Neisseria gonorrhoeae during 2009-2012 and NG-MAST genotypes in 2011 and 2012. BMC Infect Dis 2014; 14: 342.
45. European Centre for Disease Prevention and Control. Gonococcal antimicrobial susceptibility surveillance in Europe, 2015. Stockholm: ECDC. 2017.

46. Unemo M, Dillon JA. Review and international recommendation of methods for typing Neisseria gonorrhoeae isolates and their implications for improved knowledge of gonococcal epidemiology, treatment, and biology. Clin Microbiol Rev 2011; 24: 447-58

47. Unemo M, Dillon JA. Mitigating the emergence and spread of multidrug-and extensively drug-resistant gonorrhoea: is there sufficient support in resource-poor settings in Africa? Sex Transm Dis 2014; 41: 238-39.

48. Martin IM, Ison CA, Aanensen DM, et al. Rapid sequencebased identification of gonococcal transmission clusters in a large metropolitan area. J Infect Dis 2004; 189: 1497-505.

49. Jiang FX, Lan Q, Le WJ, et al. Antimicrobial susceptibility of Neisseria gonorrhoeae isolates from Hefei (2014-2015): genetic characteristics of antimicrobial resistance. BMC Infect Dis 2017; 17: 366.

50. Demczuk W, Lynch T, Martin I, et al. Whole-genome phylogenomic heterogeneity of Neisseria gonorrhoeae isolates with decreased cephalosporin susceptibility collected in Canada between 1989 and 2013. J Clin Microbiol 2015; 53: 191-200.

51. National Surveillance of Antimicrobial Susceptibilities of Neisseria gonorrhoeae Annual Summary 2014. Public Health Agency of Canada 2015; 1-45.

52. Demczuk W, Sidhu S, Unemo M, et al. Neisseria gonorrhoeae sequence typing for antimicrobial resistance, a novel antimicrobial resistance multilocus typing scheme for tracking global dissemination of N. gonorrhoeae strains. J Clin Microbiol 2017; 55: 1454-68.

53. O'Reilly LC, Goire N, Fisk RE, et al. Molecular epidemiology of Neisseria gonorrhoeae using multi-antigen sequence typing and pulse-field gel electrophoresis in highly endemic Western Australian populations. BMC Infect Dis 2015; 15: 272.

54. European Centre for Disease Prevention and Control. Molecular typing of Neisseria gonorrhoeae - results from a pilot study 2010-2011. Stockholm: ECDC, 2012.

55. European Centre for Disease Prevention and Control. Molecular typing of Neisseria gonorrhoeae - study 2013. Stockholm: ECDC, 2016.

56. Gose S, Nguyen D, Lowenberg D, et al. Neisseria gonorrhoeae and extended-spectrum cephalosporins in California: surveillance and molecular detection of mosaic penA. BMC Infect Dis 2013; 13: 570.

57. Jabeen K, Bhawan Mal P, Khan E, et al. Antimicrobial resistance and Neisseria gonorrhoeae multiantigen sequence typing (NG-MAST) genotypes in N. gonorrhoeae during 2012-2014 in Karachi, Pakistan. BMC Infect Dis 2016; 16: 353.

58. Chisholm SA, Unemo M, Quaye N, et al. Molecular epidemiological typing within the European Gonococcal Antimicrobial Resistance Surveillance Programme reveals predominance of a multidrug-resistant clone. Euro Surveill 2013; 18: pii: 20358.

59. Grad YH, Kirkcaldy RD, Trees D, et al. Genomic epidemiology of Neisseria gonorrhoeae with reduced susceptibility to cefixime in the USA: a retrospective observational study. Lancet Infect Dis 2014; 14: 220-6.

60. Harris SR, Cole MJ, Spiteri G, et al. European survey of Neisseria gonorrhoeae using whole genome sequencing identified spread of multidrug-resistant clones and provides a foundation for genomic surveillance - an observational study. Lancet Infect Dis 2018; 18: 758-68. 